\title{
Low Intensity Physical Exercise Attenuates Cardiac Remodeling and Myocardial Oxidative Stress and Dysfunction in Diabetic Rats
}

\author{
C. Gimenes, ${ }^{1,2}$ R. Gimenes, ${ }^{1}$ C. M. Rosa, ${ }^{1}$ N. P. Xavier, ${ }^{1}$ D. H. S. Campos, ${ }^{1}$ \\ A. A. H. Fernandes, ${ }^{3}$ M. D. M. Cezar, ${ }^{1}$ G. N. Guirado, ${ }^{1}$ A. C. Cicogna, ${ }^{1}$ A. H. R. Takamoto, ${ }^{1}$ \\ M. P. Okoshi, ${ }^{1}$ and K. Okoshi ${ }^{1}$ \\ ${ }^{1}$ Department of Internal Medicine, Botucatu Medical School, São Paulo State University (UNESP), S/N, \\ Rubião Junior District, 18618970 Botucatu, SP, Brazil \\ ${ }^{2}$ Sagrado Coração University, Bauru, SP, Brazil \\ ${ }^{3}$ Department of Chemistry and Biochemistry, Institute of Biosciences, São Paulo State University (UNESP), Brazil \\ Correspondence should be addressed to K. Okoshi; katashi@fmb.unesp.br
}

Received 21 November 2014; Accepted 4 January 2015

Academic Editor: Bagher Larijani

Copyright ( 92015 C. Gimenes et al. This is an open access article distributed under the Creative Commons Attribution License, which permits unrestricted use, distribution, and reproduction in any medium, provided the original work is properly cited.

\begin{abstract}
We evaluated the effects of a low intensity aerobic exercise protocol on cardiac remodeling and myocardial function in diabetic rats. Wistar rats were assigned into four groups: sedentary control (C-Sed), exercised control (C-Ex), sedentary diabetes (DM-Sed), and exercised diabetes (DM-Ex). Diabetes was induced by intraperitoneal injection of streptozotocin. Rats exercised for 9 weeks in treadmill at $11 \mathrm{~m} / \mathrm{min}, 18 \mathrm{~min} /$ day. Myocardial function was evaluated in left ventricular (LV) papillary muscles and oxidative stress in LV tissue. Statistical analysis was given by ANOVA or Kruskal-Wallis. Echocardiogram showed diabetic groups with higher LV diastolic diameter-to-body weight ratio and lower posterior wall shortening velocity than controls. Left atrium diameter was lower in DM-Ex than DM-Sed (C-Sed: $5.73 \pm$ 0.49; C-Ex: $5.67 \pm 0.53$; DM-Sed: $6.41 \pm 0.54$; DM-Ex: $5.81 \pm 0.50 \mathrm{~mm}$; $P<0.05$ DM-Sed vs C-Sed and DM-Ex). Papillary muscle function was depressed in DM-Sed compared to C-Sed. Exercise attenuated this change in DM-Ex. Lipid hydroperoxide concentration was higher in DM-Sed than C-Sed and DM-Ex. Catalase and superoxide dismutase activities were lower in diabetics than controls and higher in DM-Ex than DM-Sed. Glutathione peroxidase activity was lower in DM-Sed than C-Sed and DM-Ex. Conclusion. Low intensity exercise attenuates left atrium dilation and myocardial oxidative stress and dysfunction in type 1 diabetic rats.
\end{abstract}

\section{Introduction}

Diabetes mellitus is an important public health issue due to its high prevalence and increased morbidity and mortality. Cardiovascular disease is a major cause of death in diabetic patients [1]. Cardiac injury is caused by coronary atherosclerosis and diabetes-related cardiomyopathy [1]. As first reported by Rubler et al. [2], diabetic cardiomyopathy is a single form of heart disease characterized by left ventricular systolic and diastolic dysfunction in the absence of underlying coronary artery disease and/or hypertension. Diabetic cardiomyopathy is a common cardiac condition affecting both type 1 and type 2 diabetes patients [3].
The pathophysiology of diabetic cardiomyopathy is not completely understood as several mechanisms can be involved; these include myocyte hypertrophy, myocardial fibrosis, contractile dysfunction, calcium handling and mitochondrial function changes, and nitric oxide signaling impairment [3-8]. Hyperglycemia-induced oxidative stress is an important factor involved in diabetic cardiomyopathy [912].

Regular physical exercise is an established nonpharmacological strategy used as an adjuvant therapy in heart failure from different etiologies $[13,14]$. Clinical studies in stable chronic heart failure have shown that long-term moderate physical training attenuates abnormal cardiac remodeling 
and improves functional capacity, exercise duration, and quality of life [15-18]. In different cardiac injury models, exercise has been shown to attenuate left ventricular dilatation, myocyte hypertrophy, myocardial fibrosis, mitochondrial dysfunction, myocyte calcium handling changes, sympathoexcitation alterations, cardiac dysfunction, and inflammatory activation [19-25].

In diabetes, physical exercise reduces cardiovascular risk factors and improves glycemic control, functional capacity, and muscle strength [26-29]. However, most clinical studies in diabetes have been performed on type 2 diabetes patients $[28,30]$. In experimental studies on rats with streptozotocininduced diabetes, regular physical exercise has been shown to improve myocardial glucose homeostasis, endogenous antioxidant defenses, cardiac function, heart tolerance to ischemia, and ultrastructural extracellular matrix and mitochondrial changes [31-33]. In vivo evaluation of cardiac function is subjected to myocardial function modulation by hemodynamic and systemic metabolic abnormalities. Left ventricular isolated papillary muscle preparations allow us to properly control preload and afterload and analyze intrinsic myocardial function without the effects of systemic metabolic changes [34-36]. Furthermore, by using positive inotropic stimulation, it is also possible to evaluate myocardial contractile reserve in papillary muscle preparations [37, 38]. Therefore, in this study we evaluated the influence of a low intensity aerobic exercise protocol on in vivo cardiac remodeling and in vitro myocardial function in rats with streptozotocin-induced diabetes mellitus. As oxidative stress is associated with diabetes cardiomyopathy and can be influenced by physical exercise, we also analyzed myocardial oxidative stress in diabetic rats.

\section{Methods}

Male Wistar rats were purchased from the Central Animal House at Botucatu Medical School, UNESP. All animals were housed in a room under temperature control at $23^{\circ} \mathrm{C}$ and kept on a 12-hour light/dark cycle. Food and water were supplied ad libitum. All experiments and procedures were approved by Botucatu Medical School Ethics Committee, UNESP, Botucatu, SP, Brazil.

The rats were assigned into four groups: sedentary control (C-Sed, $n=14$ ); exercised control (C-Ex, $n=15$ ); sedentary diabetes (DM-Sed, $n=25$ ); and exercised diabetes (DM-Ex, $n=25$ ). Diabetes was induced by intraperitoneal injection of streptozotocin (Sigma, St. Louis, MO, USA) at the dose of $50 \mathrm{mg} / \mathrm{kg}$ diluted in $0.01 \mathrm{M}$ citrate buffer $\mathrm{pH} 4.5[9,39-$ 41]. Seven days after streptozotocin administration, blood glucose was measured by glucometer (advantage); only rats with glycemia > $220 \mathrm{mg} / \mathrm{dL}$ were considered diabetic and included in the study [9].

After diabetes confirmation, exercise protocol was started in a treadmill (AVS Projects, São Paulo, Brazil) as previously described [42]. The protocol was applied once a day, five days a week, for nine weeks. After the first week of animals adaptation ( $8 \mathrm{~min}, 8 \mathrm{~m} / \mathrm{min}$ ), exercise duration and speed were increased gradually up to $18 \mathrm{~min} /$ day at $11 \mathrm{~m} / \mathrm{min}$. In the first two weeks of training, the animals were subjected to low-voltage electrical stimulation to start the exercise. No animals were lost during exercise training.

Systolic blood pressure was measured at the end of experiment by the tail-cuff method [36] using an electrosphygmomanometer (Narco Bio-System, model 709-0610, International Biomedical Inc., USA).

2.1. Echocardiographic Study. Echocardiographic evaluation was performed using a commercially available echocardiograph (General Electric Medical Systems, Vivid S6, Tirat Carmel, Israel) equipped with a $5-11.5 \mathrm{MHz}$ multifrequency probe. Rats were anesthetized by intraperitoneal injection of a mixture of ketamine $(50 \mathrm{mg} / \mathrm{kg})$ and xylazine $(0.5 \mathrm{mg} / \mathrm{kg})$. A two-dimensional parasternal short-axis view of the left ventricle (LV) was obtained at the level of the papillary muscles. M-mode tracings were obtained from short-axis views of the LV at or just below the tip of the mitralvalve leaflets and at the level of the aortic valve and left atrium [43-46]. M-mode LV images were printed on a blackand-white printer at a sweep speed of $200 \mathrm{~mm} / \mathrm{s}$. All LV structures were manually measured by the same observer (KO) according to the leading-edge method of the American Society of Echocardiography. The measurements obtained were the mean of at least five cardiac cycles on the M-mode tracings. The following structural variables were measured: left atrium (LA) diameter, LV diastolic and systolic diameters (LVDD and LVSD, resp.), LV diastolic posterior wall thickness (PWT), and aortic diameter (AO). LV relative wall thickness (RWT) was calculated by the following formula: 2 $\times$ PWT/LVDD. Left ventricular mass (LVM) was calculated using the following formula: $\left[(\mathrm{LVDD}+\mathrm{PWT}+\mathrm{SWT})^{3}-\right.$ $\left.(\mathrm{LVDD})^{3}\right] \times 1.04$. Left ventricular function was assessed by the following parameters: endocardial fractional shortening (EFS), ejection fraction (EF), posterior wall shortening velocity (PWSV), early-to-late diastolic mitral inflow velocities ratio (E/A ratio), and $\mathrm{E}$ wave deceleration time (EDT). A joint assessment of diastolic and systolic LV function was performed by the myocardial performance index (Tei index).

2.2. Myocardial Functional Analysis. Two days after the echocardiographic study, intrinsic myocardial contractile performance was evaluated in isolated LV papillary muscle preparation as previously described [47-50]. Rats were anesthetized (sodium pentobarbital intraperitoneally, $50 \mathrm{mg} / \mathrm{kg}$ ) and decapitated. Hearts were quickly removed and placed in oxygenated Krebs-Henseleit solution at $28^{\circ} \mathrm{C}$. LV anterior or posterior papillary muscle was dissected free, mounted between two spring clips, and placed vertically in a chamber containing Krebs-Henseleit solution at $28^{\circ} \mathrm{C}$ and oxygenated with a mixture of $95 \% \mathrm{O}_{2}$ and $5 \% \mathrm{CO}_{2}(\mathrm{pH} 7.38)$. The composition of the Krebs-Henseleit solution in $\mathrm{mM}$ was as follows: $118.5 \mathrm{NaCl}, 4.69 \mathrm{KCl}, 1.25 \mathrm{CaCl}_{2}, 1.16 \mathrm{MgSO}_{4}, 1.18$ $\mathrm{KH}_{2} \mathrm{PO}_{4}, 5.50$ glucose, and $25.88 \mathrm{NaHCO}_{3}$. The spring clips were attached to a Kyowa model 120T-20B force transducer and a lever system which allowed for muscle length adjustment. Preparations were stimulated 12 times/min at a voltage $10 \%$ above threshold. 
After a 60-minute period, during which the preparations were permitted to shorten whilst carrying light loads, muscles were loaded to contract isometrically and stretched to the apices of their length-tension curves $\left(L_{\max }\right)$. After a 5-minute period, during which preparations performed isotonic contractions, muscles were again placed under isometric conditions and length-tension curve apex was determined. A 15minute period of stable isometric contraction was imposed prior to the experimental period. One isometric contraction was then recorded for later analysis.

The following parameters were measured from isometric contraction: peak of developed tension $\left(\mathrm{DT}, \mathrm{g} / \mathrm{mm}^{2}\right)$, resting tension (RT, $\mathrm{g} / \mathrm{mm}^{2}$ ), time to peak of tension (TPT, ms), maximum rate of tension development $\left(+\mathrm{dT} / \mathrm{dt}, \mathrm{g} / \mathrm{mm}^{2} / \mathrm{s}\right)$, and maximum rate of tension decline $\left(-\mathrm{dT} / \mathrm{dt}, \mathrm{g} / \mathrm{mm}^{2} / \mathrm{s}\right)$. To evaluate contractile reserve, mechanical papillary muscle performance was evaluated at basal condition and after the following inotropic stimulation: postrest contraction, extracellular $\mathrm{Ca}^{2+}$ concentration increase, and beta-adrenergic agonist isoproterenol addition to the nutrient solution [36].

Papillary muscle cross-sectional area (CSA) was calculated from muscle weight and length by assuming cylindrical uniformity and a specific gravity of 1.0. All force data were normalized for muscle CSA. Papillary muscles with CSA > $1.7 \mathrm{~mm}^{2}$ were excluded from analysis as muscles with CSA $>1.7 \mathrm{~mm}^{2}$ can present central core hypoxia and impaired functional performance.

After dissecting papillary muscle, atria and ventricles were separated and weighed. Fragments of lung and left and right ventricles were weighed before and after drying sessions $\left(65^{\circ} \mathrm{C}\right.$ for $\left.72 \mathrm{~h}\right)$ to evaluate the wet-to-dry weight ratio.

2.3. Morphologic Analysis. Transverse LV sections were fixed in $10 \%$ buffered formalin and embedded in paraffin. Fivemicrometer-thick sections were stained with hematoxylin and eosin. From each LV, the smallest transverse diameter was measured in at least 50 myocytes, in which the nucleus could be clearly identified [9]. Measurements were performed using a Leica microscope (magnification 40x) attached to a video camera and connected to a computer equipped with image analysis software (Image-Pro Plus 3.0, Media Cybernetics, Silver Spring, MD, USA).

2.4. Myocardial Hydroxyproline. To estimate myocardial collagen content, hydroxyproline concentration was measured in LV tissue as previously described [51, 52]. Briefly, the tissue was dried using a SpeedVac Concentrator SC 100 attached to a refrigerated condensation trap (TRL 100) and vacuum pump (VP 100, Savant Instruments, Inc., Farmingdale, NY, USA). Tissue dry weight was measured and the samples were hydrolyzed overnight at $100^{\circ} \mathrm{C}$ with $6 \mathrm{~N} \mathrm{HCl}(1 \mathrm{~mL} / 10 \mathrm{mg}$ dry tissue). A $50 \mu \mathrm{L}$ aliquot of the hydrolysate was dried in the SpeedVac Concentrator; $1 \mu \mathrm{L}$ of deionized water was added; and the sample transferred to a Teflon tube. One milliliter of potassium borate buffer ( $\mathrm{pH} 8.7)$ was added to maintain constant $\mathrm{pH}$ and the sample was oxidized with $0.3 \mathrm{~mL}$ of chloramine $\mathrm{T}$ solution at room temperature for $20 \mathrm{~min}$. The addition of $1 \mathrm{~mL}$ of $3.6 \mathrm{M}$ sodium thiosulfate and thorough mixing for $10 \mathrm{~s}$ stopped the oxidative process. The solution was saturated with $1.5 \mathrm{~g} \mathrm{KCl}$. The tubes were capped and heated in boiling water for $20 \mathrm{~min}$. After cooling to room temperature, the aqueous layer was extracted with $2.5 \mathrm{~mL}$ of toluene; $1.5 \mathrm{~mL}$ of toluene extract was transferred to a tube; and $0.6 \mathrm{~mL}$ of Ehrlich's reagent was added. The color was allowed to develop for $30 \mathrm{~min}$. Absorbance was read at $565 \mathrm{~mm}$ against a reagent blank. Deionized water and $20 \mu \mathrm{g} / \mathrm{mL}$ HOP were used as the blank and standard, respectively.

2.5. Serum Biochemical Analysis. Biochemical parameters were measured in serum using a spectrophotometer from Pharmacia Biotech (Ultrospec 2000, Cambridge, England). Analyses were performed with a CELM kit (Modern Laboratory Equipment Company, São Paulo, Brazil). Glycemia was determined by enzymatic method using glucose oxidase and peroxidase. Total cholesterol levels were measured enzymatically using cholesterol ester/oxidase. High-density lipoprotein (HDL) concentration was measured after precipitation of VLDL and LDL by the sodium phosphotungstate $/ \mathrm{Mg}^{++}$ method using an enzymatic colorimetric method that incorporates polyethylene glycol-modified cholesterol ester oxidase.

2.6. Myocardial Oxidative Stress. Oxidative stress was assessed as previously described $[9,53]$. Myocardial lipid hydroperoxide concentration was measured in medium containing methanol $90 \%(\mathrm{v} / \mathrm{v}), 250 \mu \mathrm{M}$ ammonium ferrous sulfate, $100 \mu \mathrm{M}$ xylenol orange, $25 \mathrm{mM}$ sulfuric acid, and $4 \mathrm{mM}$ butylated hydroxytoluene. The solution was incubated for $30 \mathrm{~min}$ at room temperature and measured at $560 \mathrm{~nm}$. Glutathione peroxidase was assayed in $15 \mu \mathrm{L}$ using $0.15 \mathrm{M}$ phosphate buffer, $\mathrm{pH} 7.0$, containing $5 \mathrm{mM}$ EDTA, $0.1 \mathrm{~mL}$ of $0.0084 \mathrm{M}$ NADPH, $4 \mu \mathrm{g}$ of glutathione-reductase, $1.125 \mathrm{M}$ sodium azide, and $0.15 \mathrm{M}$ glutathione reduced form (GSH) in a total volume of $0.3 \mathrm{~mL}$. Superoxide dismutase (SOD) activity was determined using its ability to inhibit reduction of nitroblue tetrazolium, in medium containing $50 \mathrm{mM}$ phosphate buffer $\mathrm{pH}$ 7.4, $0.1 \mathrm{mM}$ EDTA, $50 \mu \mathrm{M}$ NBT, $78 \mu \mathrm{M}$ $\mathrm{NADH}$, and $3.3 \mu \mathrm{M}$ phenazine methosulfate. One unit of SOD was defined as the amount of protein needed to decrease the reference rate to $50 \%$ of maximum inhibition. Enzyme activities were analyzed at $25^{\circ} \mathrm{C}$ using a microplate reader system ( $\mu$ Quant-MQX 200 with KC Junior software, Bio-Tek Instruments, Winooski, VT, USA). Catalase activity was determined in a mixture containing $10 \mathrm{mM}$ hydrogen peroxide and sodium phosphate buffer $50 \mathrm{mM}, \mathrm{pH} 7.0$, in a final volume of $0.3 \mathrm{~mL}$. Catalase unit was defined as the amount of enzyme related to $\mu \mathrm{mol} \mathrm{H}_{2} \mathrm{O}_{2}$ decomposition in a first order rate constant during $15 \mathrm{~s}$, at $240 \mathrm{~nm}$. All reagents were purchased from Sigma (St. Louis, MO, USA).

2.7. Statistical Analysis. Values were expressed as mean \pm standard deviation or median and 25th and 75th percentiles, according to normal or nonnormal distribution, respectively. Parameters with normal distribution were compared by one way ANOVA followed by the Bonferroni post hoc test and 
TABLE 1: Anatomical data.

\begin{tabular}{|c|c|c|c|c|}
\hline & $\begin{array}{c}\text { C-Sed } \\
(n=13)\end{array}$ & $\begin{array}{c}\text { C-Ex } \\
(n=12)\end{array}$ & $\begin{array}{l}\text { DM-Sed } \\
(n=12)\end{array}$ & $\begin{array}{c}\text { DM-Ex } \\
(n=16)\end{array}$ \\
\hline Final BW & $492 \pm 28$ & $467 \pm 36^{*}$ & $390 \pm 60^{*}$ & $356 \pm 50^{\# \S}$ \\
\hline LV (g) & $0.89 \pm 0.07$ & $0.86 \pm 0.06$ & $0.74 \pm 0.12^{*}$ & $0.69 \pm 0.10^{\#}$ \\
\hline LV/BW (g/kg) & $1.84 \pm 0.11$ & $1.91 \pm 0.17$ & $2.10 \pm 0.21^{*}$ & $2.18 \pm 0.21^{\#}$ \\
\hline RV (g) & $0.22 \pm 0.07$ & $0.20 \pm 0.02$ & $0.18 \pm 0.02^{*}$ & $0.16 \pm 0.04^{\#}$ \\
\hline RV/BW (g/kg) & $0.45 \pm 0.15$ & $0.45 \pm 0.06$ & $0.51 \pm 0.09$ & $0.51 \pm 0.12$ \\
\hline Atria (g) & $0.09 \pm 0.01$ & $0.10 \pm 0.01$ & $0.09 \pm 0.01$ & $0.08 \pm 0.01^{\# \S}$ \\
\hline LV wet/dry & $3.94(3.56-4.11)$ & $3.60(3.17-4.17)$ & $4.06(3.92-4.61)$ & $3.70(2.84-4.53)$ \\
\hline RV wet/dry & $3.42 \pm 0.65$ & $3.60 \pm 0.94$ & $3.96 \pm 1.02$ & $3.50 \pm 0.77$ \\
\hline Lung wet/dry & $4.55 \pm 0.50$ & $4.56 \pm 0.35$ & $4.94 \pm 0.58^{*}$ & $4.70 \pm 0.26$ \\
\hline
\end{tabular}

Values are mean \pm SD or median and 25th and 75th percentiles. C-Sed: sedentary control group; C-Ex: exercised control group; DM-Sed: sedentary diabetic group; DM-Ex: exercised diabetic group; LV: left ventricle weight; BW: body weight; RV: right ventricle weight; wet/dry: wet-to-dry weight ratio. ANOVA and Bonferroni or Kruskal-Wallis and Dunn; ${ }^{*} P<0.05$ versus C-Sed; ${ }^{\#} P<0.05$ versus $C$-Ex; ${ }^{\S} P<0.05$ versus DM-Ex.

nonnormal parameters were compared by Kruskal-Wallis and the Dunn post hoc test (comparisons of interest: C-Ex versus C-Sed, DM-Sed versus C-Sed, and DM-Ex versus DMSed). Systat 12 for Windows software was used for analyses. Statistical significance was accepted at the level of $P<$ 0.05 .

\section{Results}

The final number of animals in each experimental group was 14 in C-Sed, 13 in C-Ex, 19 in DM-Sed, and 18 in DM-Ex. Fifteen rats were excluded from the study due to nonadaptation to treadmill exercise or failure to increase glycemia after streptozotocin administration. Initial body weight (C-Sed: $327 \pm 23$; C-Ex: $331 \pm 13$; DM-Sed: $336 \pm 20$; DM-Ex: $340 \pm 20$ g; $P>0.05$ ), glycemia (C-Sed: $109 \pm 11$; C-Ex: $108 \pm 14$; DM-Sed: $103 \pm 12$; DM-Ex: $102 \pm 12 \mathrm{mg} / \mathrm{dL}$; $P>0.05$ ), and final systolic blood pressure (C-Sed: $131 \pm 18$; C-Ex: $126 \pm 13$; DM-Sed: $135 \pm 18$; DM-Ex $140 \pm 22$ mmHg; $P>0.05)$ did not differ between groups. Final glycemia was higher in diabetic groups than controls and slightly lower in DM-Ex than DM-Sed (Figure 1).

Table 1 presents anatomical data. Final body weight was lower in diabetic groups than controls and in exercised versus sedentary groups. LV and right ventricle weights were lower in diabetic groups than their respective controls. However, LV-to-body weight ratio was higher in DM than control groups. Atria weight was lower in DM-Ex than C-Ex and DMSed.

Table 2 shows echocardiographic cardiac structural and left ventricular functional parameters. Heart rate did not differ between groups. C-Ex presented lower LV diastolic diameter and higher relative wall thickness than C-Sed. Diabetic groups had higher LV diastolic diameter-to-body ratio, left atrial diameter-to-aorta diameter, and LV mass index and lower posterior wall shortening velocity than control groups. Left atrium diameter, in absolute or normalized to aorta diameter values, was lower in DM-Ex than in DM-Sed.

Table 3 shows LV papillary muscle functional data. In basal condition, $+\mathrm{dT} / \mathrm{dt}$ was lower in C-Ex than C-Sed. After

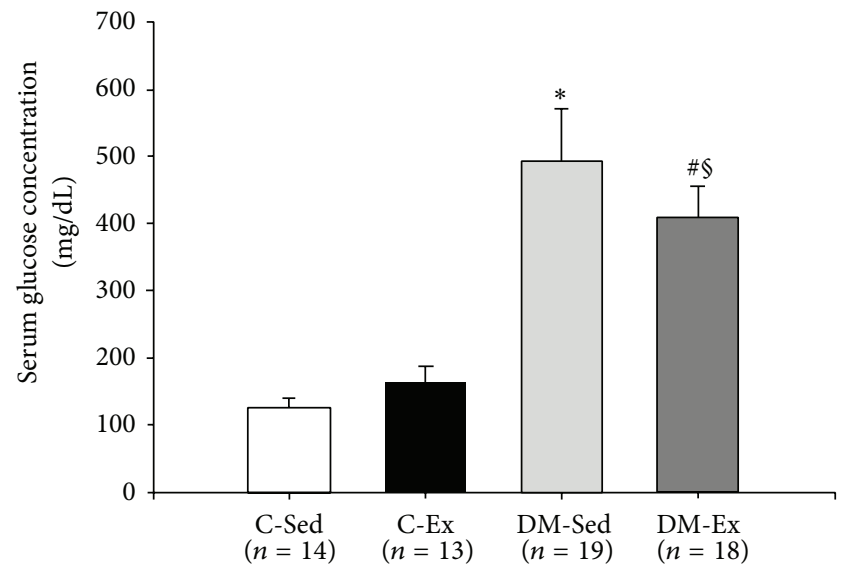

FIGURE 1: Serum glucose concentration at the end of the experiment. C-Sed: sedentary control group; C-Ex: exercised control group; DMSed: sedentary diabetic group; DM-Ex: exercised diabetic group. ANOVA and Bonferroni; ${ }^{*} P<0.05$ versus C-Sed; ${ }^{\#} P<0.05$ versus C-Ex; ${ }^{\S} P<0.05$ versus DM-Sed.

postrest contraction, $+\mathrm{dT} / \mathrm{dt}$ was lower in C-Ex and DMSed than C-Sed; DT and -dT/dt were lower in DM-Sed than C-Sed. After extracellular calcium concentration increase to $2.5 \mathrm{mM}$, TPT was greater in DM-Sed than C-Sed. After isoproterenol addition, DM-Sed presented increased TPT and reduced $+\mathrm{dT} / \mathrm{dt}$ and $-\mathrm{dT} / \mathrm{dt}$ compared to C-Sed; DM-Ex had lower-dT/dt than C-Ex.

Myocardial hydroxyproline concentration (C-Sed: $2.06 \pm$ 0.50; C-Ex: $1.96 \pm 0.09$; DM-Sed: $2.19 \pm 0.40$; DM-Ex: $2.29 \pm$ $0.36 \mathrm{mg} / \mathrm{g} ; P>0.05)$ and LV myocyte diameter (C-Sed: $12.7 \pm 0.90$; C-Ex: $13.8 \pm 1.62$; DM-Sed: $13.1 \pm 1.08$; DM-Ex: $13.7 \pm 0.69 \mu \mathrm{m} ; P>0.05)$ did not differ between groups. Total cholesterol concentration was higher in both DM groups than controls and lower in DM-Ex than DM-Sed (C-Sed: 90.5 (86.5-100); C-Ex: 98 (86.5-121); DM-Sed: 188 (182-198); DMEx: $148(136-165) \mathrm{mg} / \mathrm{dL} ; P<0.05)$. HDL-cholesterol was lower in DM-Sed than C-Sed and DM-Ex (C-Sed: 41.6 (37.849.0); C-Ex: 38.6 (37.1-45.3); DM-Sed: 21.5 (20.8-24.5); DMEx: $40.8(30.4-43.8) \mathrm{mg} / \mathrm{dL} ; P<0.05)$. 
TABLE 2: Echocardiographic data.

\begin{tabular}{|c|c|c|c|c|}
\hline & $\begin{array}{c}\text { C-Sed } \\
(n=14)\end{array}$ & $\begin{array}{c}\text { C-Ex } \\
(n=13)\end{array}$ & $\begin{array}{l}\text { DM-Sed } \\
(n=12)\end{array}$ & $\begin{array}{c}\text { DM-Ex } \\
(n=14)\end{array}$ \\
\hline HR (bpm) & $276 \pm 11$ & $285 \pm 21$ & $290 \pm 21$ & $281 \pm 20$ \\
\hline $\operatorname{LVDD}(\mathrm{mm})$ & $8.52 \pm 0.32$ & $8.13 \pm 0.47^{*}$ & $8.47 \pm 0.52$ & $8.26 \pm 0.33$ \\
\hline LVDD/BW (mm/kg) & $17.4(16.8-17.9)$ & $17.5(16.5-19.1)$ & $23.2(19.6-25.1)^{*}$ & $23.9(22.2-24.8)^{\#}$ \\
\hline $\operatorname{LVSD}(\mathrm{mm})$ & $4.16 \pm 0.52$ & $3.97 \pm 0.40$ & $4.26 \pm 0.59$ & $4.15 \pm 0.50$ \\
\hline LVPWT (mm) & $1.41 \pm 0.05$ & $1.45 \pm 0.07$ & $1.49 \pm 0.16$ & $1.44 \pm 0.15$ \\
\hline LVMI (g/kg) & $1.77(1.74-1.90)$ & $1.84(1.70-2.03)$ & $2.43(2.10-2.75)^{*}$ & $2.38(2.26-2.60)^{\#}$ \\
\hline LVRWT & $0.33 \pm 0.02$ & $0.36 \pm 0.02^{*}$ & $0.35 \pm 0.04$ & $0.35 \pm 0.04$ \\
\hline $\mathrm{LA}(\mathrm{mm})$ & $5.73 \pm 0.49$ & $5.67 \pm 0.53$ & $6.41 \pm 0.54^{*}$ & $5.81 \pm 0.50^{\S}$ \\
\hline $\mathrm{LA} / \mathrm{AO}$ & $1.45 \pm 0.12$ & $1.49 \pm 0.12$ & $1.74 \pm 0.12^{*}$ & $1.60 \pm 0.03^{\# \S}$ \\
\hline EFS (\%) & $51.2 \pm 5.14$ & $51.3 \pm 2.98$ & $49.9 \pm 4.55$ & $49.8 \pm 5.33$ \\
\hline $\mathrm{EF}$ & $0.88 \pm 0.04$ & $0.88 \pm 0.02$ & $0.87 \pm 0.03$ & $0.88 \pm 0.04$ \\
\hline PWSV $(\mathrm{mm} / \mathrm{s})$ & $38.8 \pm 4.02$ & $39.4 \pm 4.54$ & $34.1 \pm 2.85^{*}$ & $35.7 \pm 4.52^{\#}$ \\
\hline $\mathrm{E} / \mathrm{A}$ & $1.53 \pm 0.22$ & $1.65 \pm 0.32$ & $1.35 \pm 0.22$ & $1.48 \pm 0.24$ \\
\hline $\mathrm{EDT}(\mathrm{ms})$ & $47.4 \pm 5.79$ & $47.6 \pm 6.70$ & $44.7 \pm 6.07$ & $47.4 \pm 8.71$ \\
\hline Tei index & $0.48 \pm 0.06$ & $0.52 \pm 0.08$ & $0.52 \pm 0.05$ & $0.58 \pm 0.10$ \\
\hline
\end{tabular}

Values are mean \pm SD or median and 25th and 75th percentiles. C-Sed: sedentary control group; C-Ex: exercised control group; DM-Sed: sedentary diabetic group; DM-Ex: exercised diabetic group; HR: heart rate; LVDD and LVSD: left ventricular (LV) diastolic and systolic diameters, respectively; BW: body weight; LVPWT: LV posterior wall thickness; LVMI: LV mass index; LVRWT: LV relative wall thickness; LA: left atrium diameter; AO: aorta diameter; EFS: LV endocardial fractional shortening; EF: LV ejection fraction; PWSV: LV posterior wall shortening velocity; E/A: ratio of early (E wave) to late (A wave) diastolic mitral inflow velocities; EDT: E wave deceleration time. ANOVA and Bonferroni or Kruskal-Wallis and Dunn; ${ }^{*} P<0.05$ versus C-Sed; ${ }^{\#} P<0.05$ versus $C$-Ex; ${ }^{\S} P<0.05$ versus DM-Ex.

TABLE 3: Isolated papillary muscle data at basal condition and after positive inotropic stimulation.

\begin{tabular}{|c|c|c|c|c|c|}
\hline & & $\begin{array}{c}\text { C-Sed } \\
(n=14)\end{array}$ & $\begin{array}{c}\text { C-Ex } \\
(n=13)\end{array}$ & $\begin{array}{l}\text { DM-Sed } \\
(n=12)\end{array}$ & $\begin{array}{c}\text { DM-Ex } \\
(n=14)\end{array}$ \\
\hline \multirow{5}{*}{ Basal } & DT $\left(\mathrm{g} / \mathrm{mm}^{2}\right)$ & $8.57 \pm 2.13$ & $7.13 \pm 1.82$ & $7.35 \pm 1.13$ & $7.23 \pm 1.53$ \\
\hline & TPT (ms) & $169 \pm 15$ & $175 \pm 15$ & $183 \pm 16$ & $176 \pm 16$ \\
\hline & $+\mathrm{dT} / \mathrm{dt}\left(\mathrm{g} / \mathrm{mm}^{2} / \mathrm{s}\right)$ & $99.9 \pm 29.1$ & $78.9 \pm 17.0^{*}$ & $78.9 \pm 16.8^{*}$ & $76.6 \pm 17.4$ \\
\hline & $-\mathrm{dT} / \mathrm{dt}\left(\mathrm{g} / \mathrm{mm}^{2} / \mathrm{s}\right)$ & $32.2(29.8-42.6)$ & $29.8(25.3-37.0)$ & $27.1(23.8-33.6)$ & $28.2(24.2-35.7)$ \\
\hline & $\mathrm{RT}\left(\mathrm{g} / \mathrm{mm}^{2}\right)$ & $1.02(0.81-1.09)$ & $0.90(0.66-1.04)$ & $0.88(0.75-0.97)$ & $0.88(0.70-0.97)$ \\
\hline \multirow{5}{*}{ PP30 } & DT $\left(\mathrm{g} / \mathrm{mm}^{2}\right)$ & $10.56 \pm 2.37$ & $8.68 \pm 2.59$ & $8.45 \pm 1.56^{*}$ & $8.45 \pm 1.96$ \\
\hline & TPT $(\mathrm{ms})$ & $160(160-180)$ & $180(170-193)$ & $180(170-190)$ & $170(170-193)$ \\
\hline & $+\mathrm{dT} / \mathrm{dt}\left(\mathrm{g} / \mathrm{mm}^{2} / \mathrm{s}\right)$ & $122 \pm 32.9$ & $94.5 \pm 25.6^{*}$ & $90.8 \pm 21.1^{*}$ & $88.8 \pm 21.2$ \\
\hline & $-\mathrm{dT} / \mathrm{dt}\left(\mathrm{g} / \mathrm{mm}^{2} / \mathrm{s}\right)$ & $39.1 \pm 12.2$ & $34.1 \pm 9.14$ & $29.4 \pm 6.88^{*}$ & $30.4 \pm 7.14$ \\
\hline & $\mathrm{RT}\left(\mathrm{g} / \mathrm{mm}^{2}\right)$ & $0.98(0.84-1.09)$ & $0.91(0.56-1.04)$ & $0.89(0.75-0.94)$ & $0.89(0.69-1.05)$ \\
\hline \multirow{5}{*}{$2.5 \mathrm{mM}\left[\mathrm{Ca}^{2+}\right]_{0}$} & $\mathrm{DT}\left(\mathrm{g} / \mathrm{mm}^{2}\right)$ & $8.97(8.35-10.6)$ & $8.80(7.56-12.1)$ & $7.73(6.58-9.07)$ & $8.97(6.20-11.3)$ \\
\hline & TPT $(\mathrm{ms})$ & $160(160-180)$ & $170(170-180)$ & $195(170-200)^{*}$ & $170(160-180)$ \\
\hline & $+\mathrm{dT} / \mathrm{dt}\left(\mathrm{g} / \mathrm{mm}^{2} / \mathrm{s}\right)$ & $119 \pm 28.4$ & $108 \pm 36.0$ & $90.3 \pm 22.9$ & $84.6 \pm 37.2$ \\
\hline & $-\mathrm{dT} / \mathrm{dt}\left(\mathrm{g} / \mathrm{mm}^{2} / \mathrm{s}\right)$ & $36.2(32.4-46.5)$ & $38.3(31.4-55.8)$ & $32.0(25.7-38.6)$ & $24.6(20.8-39.9)$ \\
\hline & $\mathrm{RT}\left(\mathrm{g} / \mathrm{mm}^{2}\right)$ & $0.89 \pm 0.30$ & $0.72 \pm 0.34$ & $0.68 \pm 0.19$ & $0.76 \pm 0.35$ \\
\hline \multirow{5}{*}{$10^{-6} \mathrm{M}$ Iso } & DT $\left(\mathrm{g} / \mathrm{mm}^{2}\right)$ & $7.80(7.08-9.86)$ & $6.71(5.53-9.48)$ & $7.14(5.95-8.46)$ & $6.91(6.45-8.81)$ \\
\hline & $\mathrm{TPT}(\mathrm{ms})$ & $149 \pm 13$ & $160 \pm 17$ & $167 \pm 9^{*}$ & $167 \pm 14$ \\
\hline & $+\mathrm{dT} / \mathrm{dt}\left(\mathrm{g} / \mathrm{mm}^{2} / \mathrm{s}\right)$ & $117 \pm 25.6$ & $99.5 \pm 25.1$ & $92.7 \pm 22.1^{*}$ & $91.1 \pm 17.7$ \\
\hline & $-\mathrm{dT} / \mathrm{dt}\left(\mathrm{g} / \mathrm{mm}^{2} / \mathrm{s}\right)$ & $58.1 \pm 11.5$ & $55.3 \pm 13.6$ & $44.4 \pm 12.4^{*}$ & $44.3 \pm 9.67^{\#}$ \\
\hline & $\mathrm{RT}\left(\mathrm{g} / \mathrm{mm}^{2}\right)$ & $0.85 \pm 0.32$ & $0.60 \pm 0.31$ & $0.65 \pm 0.18$ & $0.73 \pm 0.34$ \\
\hline
\end{tabular}

Values are mean \pm SD or median and 25th and 75th percentiles. C-Sed: sedentary control group; C-Ex: exercised control group; DM-Sed: sedentary diabetic group; DM-Ex: exercised diabetic group; DT: peak of developed tension; TPT: time to peak of tension; +dT/dt: maximum rate of tension development; -dT/dt: maximum rate of tension decline; RT: resting tension. Basal: isometric contraction with $1.25 \mathrm{mM}$ extracellular calcium concentration; PP30: postrest contraction of $30 \mathrm{~s} ; 2.5 \mathrm{mM}\left[\mathrm{Ca}^{2+}\right]_{0}$ : isometric contraction with $2.5 \mathrm{mM}$ extracellular calcium concentration; $10^{-6} \mathrm{M}$ Iso: isometric contraction with $10^{-6} \mathrm{M}$ isoproterenol added to the nutrient solution. ANOVA and Bonferroni or Kruskal-Wallis and Dunn; ${ }^{*} P<0.05$ versus C-Sed; ${ }^{\#} P<0.05$ versus C-Ex. 

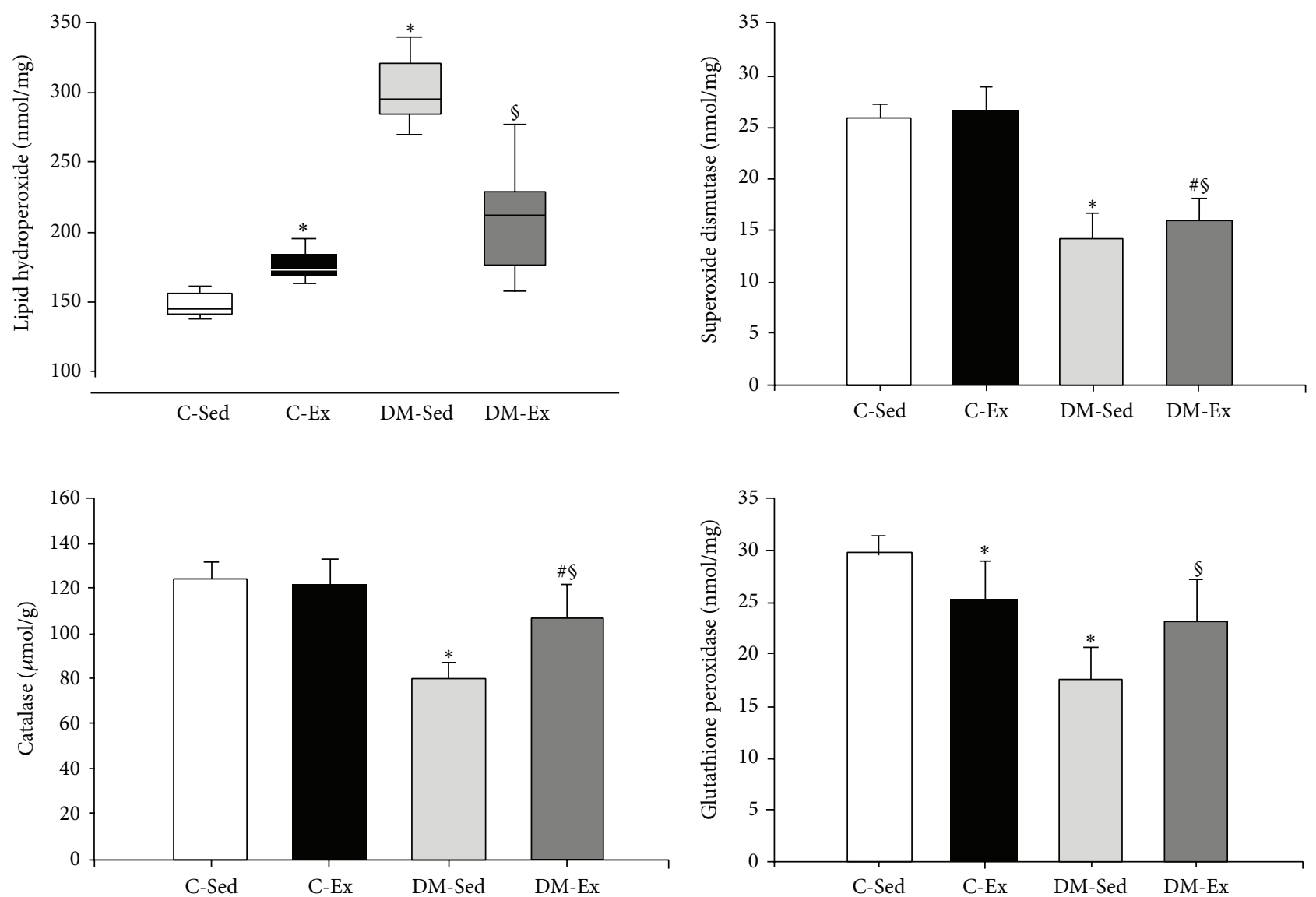

FIGURE 2: Oxidative stress markers assessed in the left ventricular myocardium. C-Sed: sedentary control group; C-Ex: exercised control group; DM-Sed: sedentary diabetic group; DM-Ex: exercised diabetic group. ANOVA and Bonferroni or Kruskal-Wallis and Dunn (lipid hydroperoxide concentration); ${ }^{*} P<0.05$ versus $C$-Sed; ${ }^{\#} P<0.05$ versus $C$-Ex; ${ }^{\circledR} P<0.05$ versus DM-Sed.

Oxidative stress data are shown in Figure 2. Lipid hydroperoxide concentration was higher in C-Ex and DM-Sed than C-Sed and lower in DM-Ex than DM-Sed. Catalase and superoxide dismutase activity was lower in DM groups than their respective controls and higher in DM-Ex than DM-Sed. Glutathione peroxidase activity was lower in C-Ex and DMSed than C-Sed and higher in DM-Ex than DM-Sed.

\section{Discussion}

In this study, we evaluated the effects of a low intensity physical exercise protocol on cardiac remodeling and myocardial oxidative stress and function in type 1 diabetic rats.

We used a low intensity exercise protocol for nine weeks including one week of adaptation. Low intensity exercise protocols have been used in diabetic rats as they may not tolerate more extensive or intense periods of exercise $[42,54,55]$. Low intensity appeared more effective than high intensity exercise training to reduce diabetes-related inflammation in serum and skeletal muscles [56]. In our study, the low intensity exercise protocol was sufficient to reduce myocardial oxidative stress and to improve cardiac remodeling and myocardial function.
As expected, diabetic animals presented heightened glycemia increase and reduced body weight and physical exercise slightly attenuated serum glucose increase in DMEx group. As blood pressure did not differ between groups, we can discard the influence of hemodynamic changes on exercise-induced cardiac changes.

Transthoracic echocardiogram was performed to analyze in vivo cardiac structures and left ventricular function. In the C-Ex group, physical exercise induced a slight reduction in absolute LV diastolic diameter values and an increase in LV relative wall thickness with unchanged systolic or diastolic function. These results suggest a change towards LV concentric remodeling.

DM-Sed presented LV hypertrophy with dilated left cardiac chambers, characterized by increased LV mass index, LV diastolic diameter-to-body weight ratio, and left atrial diameter, with reduced systolic function, characterized by decreased LV posterior wall shortening velocity, compared to C-Sed. A similar echocardiographic pattern of dilated cardiomyopathy has often been observed in experimental diabetes mellitus [57-61]. The fact that posterior wall shortening velocity was the only changed functional variable suggests that cardiac function was evaluated early during diabetes cardiomyopathy development. The higher lung wet-to-dry 
weight ratio in DM-Sed suggests the presence of pulmonary congestion and reinforces the LV dysfunction in DM-Sed. Myocardial function analysis in LV papillary muscle preparations showed lower developed tension in postrest contraction; lower $+\mathrm{dT} / \mathrm{dt}$ in basal condition, postrest contraction, and after isoproterenol stimulation; lower - dT/dt in postrest contraction and after isoproterenol stimulation; and higher time to peak tension after calcium and isoproterenol stimulation in DM-Sed compared to C-Sed. These results allow us to conclude that diabetes-induced systolic and diastolic myocardial dysfunction is responsible for the echocardiographic pattern of dilated cardiomyopathy observed in the in vivo evaluation.

The echocardiographic study revealed that left atrium diameter was lower in DM-Ex than DM-Sed. Left atrium dilation is often caused by an increase in LV diastolic pressure, which may result from alterations in LV diastolic and/or systolic function. In clinical studies, left atrium dimension plays an important role in LV diastolic function evaluation. In fact, an increase in left atrium diameter can be considered an early indicator of diastolic dysfunction [62]. Physical exercise attenuated myocardial dysfunction as DM-Ex had papillary muscle parameter values between those of DMSed and C-Ex but not significantly different from either group, except for lower - dT/dt after isoproterenol stimulation than C-Ex. In DM-Ex, the pulmonary congestion marker (wet/dry lung weight ratio) also presented values between those of DM-Sed and C-Ex. We can therefore conclude that exercise attenuated lung congestion, left atrium dilation, and systolic and diastolic myocardial dysfunction in diabetic rats. Physical exercise has been previously shown to improve cardiac function in diabetic rats and attenuate diabetesinduced impaired fractional shortening, contraction velocity, and relaxation time in isolated cardiomyocytes [55, 63].

In diabetes, several myocardial changes can be involved in myocardial dysfunction. In this study, we evaluated myocyte hypertrophy, myocardial fibrosis, and oxidative stress as mechanisms potentially involved in the benefits of physical exercise.

Myocardial fibrosis was assessed by measuring myocardial concentration of hydroxyproline, an amino acid, and the main component of the collagen molecule which can only be found in small concentrations in a limited number of other proteins. We observed no difference in hydroxyproline concentration between groups. Myocyte hypertrophy, assessed by measuring the lower transverse diameter, also did not differ between groups. We can therefore conclude that myocardial fibrosis and myocyte hypertrophy are not involved in the cardiac effects of physical exercise. Some authors have previously observed increased myocardial interstitial collagen in streptozotocin-induced diabetes rats [33, $64,65]$ and attenuation by physical exercise $[33,65]$. Different data can result from the different methods used to evaluate myocardial fibrosis such as ultrastructural analysis [33], protein expression measurement by western blot technique [64], or morphometric analysis using Sirius-red staining [65].

We next evaluated myocardial oxidative stress status. Diabetes increased oxidative stress as lipid hydroperoxide concentration was higher and the activity of antioxidant enzymes superoxide dismutase, catalase, and glutathione peroxidase was lower in DM-Sed than C-Sed. Increased myocardial oxidative stress has previously been reported in diabetic rats $[59,66]$. We have previously shown that myocardial oxidative stress in aged diabetic spontaneously hypertensive rats was associated with impaired myocardial and ventricular function [9]. Oxidative stress is a state of imbalance between reactive oxygen species production and endogenous antioxidant capacity [67]. Our data showed that diabetes induced both increased reactive oxygen species production and decreased antioxidant capacity due to reduced antioxidant enzymes activity.

Oxidative stress is a common underlying mechanism in many diseases including cardiovascular diseases. Current knowledge indicates that oxidative stress plays a role as a major determinant of the onset and progression of diabetesassociated cardiovascular alterations $[3,8,10]$. Although it has been established that oxidative stress plays a major role in the development of cardiovascular diseases, clinical studies have failed to show improved outcomes after antioxidant supplementation in preventing or treating cardiovascular diseases $[67,68]$. While the mechanisms responsible for these poor results are not clear, researchers have directed their attention towards nonpharmacological therapy to reduce oxidative stress, with physical exercise attracting great interest. Recent experimental studies have shown that chronic moderate exercise can decrease oxidative stress in skeletal muscles $[69,70]$. In this study, we observed that physical exercise prevented an increase in myocardial lipid peroxidation and attenuated a decrease in antioxidant enzymes activity. Additional studies are needed to elucidate the mechanisms involved in exerciseinduced decrease in myocardial oxidative stress during diabetes mellitus.

Studies have shown that increased oxidative stress jeopardizes myocardial function through mechanisms such as microvascular damage, abnormalities in calcium homeostasis, and endothelial dysfunction [11]. Although a causative role could not be demonstrated in this study, myocardial oxidative stress may have been involved in the exerciseinduced improvement in myocardial function and cardiac remodeling in diabetes rats. Our data therefore support the idea of the beneficial role of low intensity exercise in myocardial function and cardiac remodeling in rats with unmanaged type 1 diabetes mellitus.

In conclusion, low intensity physical exercise attenuates myocardial oxidative stress, lung congestion, left atrium dilation, and myocardial dysfunction in type 1 diabetic rats.

\section{Conflict of Interests}

The authors declare that there is no conflict of interests regarding the publication of this paper.

\section{Acknowledgments}

The authors are grateful to Jose C Georgette and Fernanda CF Moretto for their technical assistance and Colin Edward Knaggs for English editing. Financial support was provided 
by CNPq (480829/2013-6, 306845/2012-1, and 306857/2012$0)$ and FAPESP (2009/54506-7).

\section{References}

[1] A. S. Go, D. Mozaffarian, V. L. Roger et al., "Heart disease and stroke statistics-2014 update: a report from the American Heart Association," Circulation, vol. 129, no. 3, pp. e28-e292, 2014.

[2] S. Rubler, J. Dlugash, Y. Z. Yuceoglu, T. Kumral, A. W. Branwood, and A. Grishman, "New type of cardiomyopathy associated with diabetic glomerulosclerosis," The American Journal of Cardiology, vol. 30, no. 6, pp. 595-602, 1972.

[3] T. Miki, S. Yuda, H. Kouzu, and T. Miura, "Diabetic cardiomyopathy: pathophysiology and clinical features," Heart Failure Reviews, vol. 18, no. 2, pp. 149-166, 2013.

[4] M. L. Ward and D. J. Crossman, "Mechanisms underlying the impaired contractility of diabetic cardiomyopathy," World Journal of Cardiology, vol. 6, no. 7, pp. 577-584, 2014.

[5] A. Zarain-Herzberg, G. García-Rivas, and R. Estrada-Avilés, "Regulation of SERCA pumps expression in diabetes," Cell Calcium, vol. 56, no. 5, pp. 302-310, 2014.

[6] J. G. Duncan, "Mitochondrial dysfunction in diabetic cardiomyopathy," Biochimica et Biophysica Acta-Molecular Cell Research, vol. 1813, no. 7, pp. 1351-1359, 2011.

[7] S. Khanna, G. B. Singh, and M. Khullar, "Nitric oxide synthases and diabetic cardiomyopathy," Nitric Oxide C, vol. 43, pp. 29-34, 2014.

[8] R. Tarquini, C. Lazzeri, L. Pala, C. M. Rotella, and G. F. Gensini, "The diabetic cardiomyopathy," Acta Diabetologica, vol. 48, no. 3, pp. 173-181, 2011.

[9] C. M. Rosa, N. P. Xavier, D. H. Campos et al., "Diabetes mellitus activates fetal gene program and intensifies cardiac remodeling and oxidative stress in aged spontaneously hypertensive rats," Cardiovascular Diabetology, vol. 12, no. 1, article 152, 2013.

[10] S. Boudina and E. D. Abel, "Diabetic cardiomyopathy, causes and effects," Reviews in Endocrine and Metabolic Disorders, vol. 11, no. 1, pp. 31-39, 2010.

[11] K. Watanabe, R. A. Thandavarayan, M. Harima et al., "Role of differential signaling pathways and oxidative stress in diabetic cardiomyopathy," Current Cardiology Reviews, vol. 6, no. 4, pp. 280-290, 2010.

[12] C. T. Zhao, M. Wang, C. W. Siu et al., "Myocardial dysfunction in patients with type 2 diabetes mellitus: role of endothelial progenitor cells and oxidative stress," Cardiovascular Diabetology, vol. 11, article 147, 2012.

[13] C. W. Yancy, M. Jessup, B. Bozkurt et al., "2013 ACCF/AHA guideline for the management of heart failure: executive summary: a report of the American college of cardiology foundation/American Heart Association task force on practice guidelines," Circulation, vol. 128, no. 16, pp. 1810-1852, 2013.

[14] M. F. Piepoli, C. Davos, D. P. Francis, and A. J. Coats, "Exercise training meta-analysis of trials in patients with chronic heart failure (ExTraMATCH)," British Medical Journal, vol. 328, article 189, 2004.

[15] P. Giannuzzi, P. L. Temporelli, U. Corrà, and L. Tavazzi, "Antiremodeling effect of long-term exercise training in patients with stable chronic heart failure: results of the exercise in left ventricular dysfunction and chronic heart failure (ELVD-CHF) trial," Circulation, vol. 108, no. 5, pp. 554-559, 2003.
[16] U. Wisløff, A. Støylen, J. P. Loennechen et al., "Superior cardiovascular effect of aerobic interval training versus moderate continuous training in heart failure patients: a randomized study," Circulation, vol. 115, no. 24, pp. 3086-3094, 2007.

[17] K. E. Flynn, I. L. Piña, D. J. Whellan et al., "Effects of exercise training on health status in patients with chronic heart failure HF-ACTION randomized controlled trial," Journal of the American Medical Association, vol. 301, no. 14, pp. 1451-1459, 2009.

[18] I. Nishi, T. Noguchi, Y. Iwanaga et al., "Effects of exercise training in patients with chronic heart failure and advanced left ventricular systolic dysfunction receiving $\beta$-blockers," Circulation Journal, vol. 75, no. 7, pp. 1649-1655, 2011.

[19] T. L. Llewellyn, N. M. Sharma, H. Zheng, and K. P. Patel, "Effects of exercise training on SFO-mediated sympathoexcitation during chronic heart failure," The American Journal of PhysiologyHeart and Circulatory Physiology, vol. 306, no. 1, pp. H121-H131, 2014.

[20] R. B. Nunes, J. P. Alves, L. P. Kessler, and P. dal Lago, "Aerobic exercise improves the inflammatory profile correlated with cardiac remodeling and function in chronic heart failure rats," Clinics, vol. 68, no. 6, pp. 876-882, 2013.

[21] X. Xu, W. Wan, A. S. Powers et al., "Effects of exercise training on cardiac function and myocardial remodeling in post myocardial infarction rats," Journal of Molecular and Cellular Cardiology, vol. 44, no. 1, pp. 114-122, 2008.

[22] J. Kraljevic, J. Marinovic, D. Pravdic et al., "Aerobic interval training attenuates remodelling and mitochondrial dysfunction in the post-infarction failing rat heart," Cardiovascular Research, vol. 99, no. 1, pp. 55-64, 2013.

[23] L. V. Rossoni, R. A. F. Oliveira, R. R. Caffaro et al., "Cardiac benefits of exercise training in aging spontaneously hypertensive rats," Journal of Hypertension, vol. 29, no. 12, pp. 2349-2358, 2011.

[24] C. D. Garciarena, O. A. Pinilla, M. B. Nolly et al., "Endurance training in the spontaneously hypertensive rat. Conversion of pathological into physiological cardiac hypertrophy," Hypertension, vol. 53, no. 4, pp. 708-714, 2009.

[25] A. Medeiros, N. P. L. Rolim, R. S. F. Oliveira et al., "Exercise training delays cardiac dysfunction and prevents calcium handling abnormalities in sympathetic hyperactivity-induced heart failure mice," Journal of Applied Physiology, vol. 104, no. 1, pp. 103-109, 2008.

[26] L. Schwingshackl, B. Missbach, S. Dias, J. König, and G. Hoffmann, "Impact of different training modalities on glycaemic control and blood lipids in patients with type 2 diabetes: a systematic review and network meta-analysis," Diabetologia, vol. 57, no. 9, pp. 1789-1797, 2014.

[27] S. M. Reyna, P. Tantiwong, E. Cersosimo, R. A. Defronzo, A. Sriwijitkamol, and N. Musi, "Short-term exercise training improves insulin sensitivity but does not inhibit inflammatory pathways in immune cells from insulin-resistant subjects," Journal of Diabetes Research, vol. 2013, Article ID 107805, 8 pages, 2013.

[28] American Diabetes Association, "Standards of medical care in diabetes-2014," Diabetes Care, vol. 37, supplement 1, pp. S14S80, 2014.

[29] J. W. Sacre, C. L. Jellis, C. Jenkins et al., "A six-month exercise intervention in subclinical diabetic heart disease: effects on exercise capacity, autonomic and myocardial function," Metabolism, vol. 63, no. 9, pp. 1104-1114, 2014. 
[30] S. R. Colberg, R. J. Sigal, B. Fernhall et al., "Exercise and type 2 diabetes: the American College of Sports Medicine and the American Diabetes Association: joint position statement executive summary," Diabetes Care, vol. 33, no. 12, pp. 26922696, 2010.

[31] D. J. Paulson, S. J. Kopp, D. G. Peace, and J. P. Tow, "Improved postischemic recovery of cardiac pump function in exercised trained diabetic rats," Journal of Applied Physiology, vol. 65, no. 1, pp. 187-193, 1988.

[32] T. L. Broderick, P. Poirier, and M. Gillis, "Exercise training restores abnormal myocardial glucose utilization and cardiac function in diabetes," Diabetes Metabolism Research and Reviews, vol. 21, no. 1, pp. 44-50, 2005.

[33] Y. M. Searls, I. V. Smirnova, B. R. Fegley, and L. Stehno-Bittel, "Exercise attenuates diabetes-induced ultrastructural changes in rat cardiac tissue," Medicine \& Science in Sports \& Exercise, vol. 36, no. 11, pp. 1863-1870, 2004.

[34] K. Okoshi, L. S. Matsubara, M. P. Okoshi et al., "Food restriction-induced myocardial dysfunction demonstrated by the combination of in vivo and in vitro studies," Nutrition Research, vol. 22, no. 11, pp. 1353-1364, 2002.

[35] K. Okoshi, J. R. Fioretto, M. P. Okoshi et al., "Food restriction induces in vivo ventricular dysfunction in spontaneously hypertensive rats without impairment of in vitro myocardial contractility," Brazilian Journal of Medical and Biological Research, vol. 37, no. 4, pp. 607-613, 2004.

[36] M. D. M. Cezar, R. L. Damatto, P. F. Martinez et al., "Aldosterone blockade reduces mortality without changing cardiac remodeling in spontaneously hypertensive rats," Cellular Physiology and Biochemistry, vol. 32, no. 5, pp. 1275-1287, 2013.

[37] A. L. Gut, M. P. Okoshi, C. R. Padovani, F. F. Aragon, and A. C. Cicogna, "Myocardial dysfunction induced by food restriction is related to calcium cycling and beta-adrenergic system changes," Nutrition Research, vol. 23, no. 7, pp. 911-919, 2003.

[38] A. L. Gut, M. M. Sugizaki, M. P. Okoshi et al., "Food restriction impairs myocardial inotropic response to calcium and $\beta$ adrenergic stimulation in spontaneously hypertensive rats," Nutrition Research, vol. 28, no. 10, pp. 722-727, 2008.

[39] A. A. H. Fernandes, E. L. B. Novelli, K. Okoshi et al., "Influence of rutin treatment on biochemical alterations in experimental diabetes," Biomedicine \& Pharmacotherapy, vol. 64, no. 3, pp. 214-219, 2010.

[40] M. H. M. Yousif, B. Makki, A. Z. El-Hashim, S. Akhtar, and I. F. Benter, "Chronic treatment with Ang-(1-7) reverses abnormal reactivity in the corpus cavernosum and normalizes diabetesinduced changes in the protein levels of ACE, ACE2, ROCK1, ROCK2 and omega-hydroxylase in a rat model of type 1 diabetes," Journal of Diabetes Research, vol. 2014, Article ID 142154, 10 pages, 2014.

[41] J. F. Hu, G. J. Zhang, L. Wang et al., "Ethanol at low concentration attenuates diabetes induced lung injury in rats model," Journal of Diabetes Research, vol. 2014, Article ID 107152, 6 pages, 2014.

[42] G. Tancrede, S. Rousseau-Migneron, and A. Nadeau, "Beneficial effects of physical training in rats with a mild streptozotocininduced diabetes mellitus," Diabetes, vol. 31, no. 5, pp. 406-409, 1982.

[43] M. M. Sugizaki, R. F. Carvalho, F. F. Aragon et al., "Myocardial dysfunction induced by food restriction is related to morphological damage in normotensive middle-aged rats," Journal of Biomedical Science, vol. 12, no. 4, pp. 641-649, 2005.
[44] A. R. R. Lima, P. F. Martinez, K. Okoshi et al., "Myostatin and follistatin expression in skeletal muscles of rats with chronic heart failure," International Journal of Experimental Pathology, vol. 91, no. 1, pp. 54-62, 2010.

[45] P. F. Martinez, K. Okoshi, L. A. M. Zornoff et al., "Echocardiographic detection of congestive heart failure in postinfarction rats," Journal of Applied Physiology, vol. 111, no. 2, pp. 543-551, 2011.

[46] S. A. O. Junior, M. dal Pai-Silva, P. F. Martinez et al., "Dietinduced obesity causes metabolic, endocrine and cardiac alterations in spontaneously hypertensive rats," Medical Science Monitor, vol. 16, no. 12, pp. BR367-BR373, 2010.

[47] K. Okoshi, H. B. Ribeiro, M. P. Okoshi et al., "Improved systolic ventricular function with normal myocardial mechanics in compensated cardiac hypertrophy," Japanese Heart Journal, vol. 45, no. 4, pp. 647-656, 2004.

[48] S. A. R. De Paiva, L. A. M. Zornoff, M. P. Okoshi et al., "Ventricular remodeling induced by retinoic acid supplementation in adult rats," The American Journal of Physiology-Heart and Circulatory Physiology, vol. 284, no. 6, pp. H2242-H2246, 2003.

[49] M. P. Okoshi, K. Okoshi, V. D. Pai, M. D. Pai-Silva, L. S. Matsubara, and A. C. Cicogna, "Mechanical, biochemical, and morphological changes in the heart from chronic foodrestricted rats," Canadian Journal of Physiology and Pharmacology, vol. 79, no. 9, pp. 754-760, 2001.

[50] A. C. Cicogna, C. R. Padovani, K. Okoshi, L. S. Matsubara, F. F. Aragon, and M. P. Okoshi, "The influence of temporal food restriction on the performance of isolated cardiac muscle," Nutrition Research, vol. 21, no. 4, pp. 639-648, 2001.

[51] J. R. Fioretto, S. S. Querioz, C. R. Padovani, L. S. Matsubara, K. Okoshi, and B. B. Matsubara, "Ventricular remodeling and diastolic myocardial dysfunction in rats submitted to proteincalorie malnutrition," The American Journal of PhysiologyHeart and Circulatory Physiology, vol. 282, no. 4, pp. H1327H1333, 2002.

[52] M. P. Okoshi, L. S. Matsubara, M. Franco, A. C. Cicogna, and B. B. Matsubara, "Myocyte necrosis is the basis for fibrosis in renovascular hypertensive rats," Brazilian Journal of Medical and Biological Research, vol. 30, no. 9, pp. 1135-1144, 1997.

[53] P. F. Martinez, C. Bonomo, D. M. Guizoni et al., "Influence of $N$ acetylcysteine on oxidative stress in slow-twitch soleus muscle of heart failure rats," Cellular Physiology and Biochemistry, vol. 35, no. 1, pp. 148-159, 2015.

[54] K. L. D. de Angelis, A. R. Oliveira, P. Dall'Ago et al., "Effects of exercise training on autonomic and myocardial dysfunction in streptozotocin-diabetic rats," Brazilian Journal of Medical and Biological Research, vol. 33, no. 6, pp. 635-641, 2000.

[55] R. Loganathan, M. Bilgen, B. Al-Hafez, S. V. Zhero, M. D. Alenezy, and I. V. Smirnova, "Exercise training improves cardiac performance in diabetes: in vivo demonstration with quantitative cine-MRI analyses," Journal of Applied Physiology, vol. 102, no. 2, pp. 665-672, 2007.

[56] J.-S. Kim, Y.-H. Lee, J.-C. Kim, Y.-H. Ko, C.-S. Yoon, and H.K. Yi, "Effect of exercise training of different intensities on antiinflammatory reaction in streptozotocin-induced diabetic rats," Biology of Sport, vol. 31, no. 1, pp. 73-79, 2014.

[57] I. I. Joffe, K. E. Travers, C. L. Perreault-Micale et al., "Abnormal cardiac function in the streptozotocin-induced, non-insulindependent diabetic rat: noninvasive assessment with Doppler echocardiography and contribution of the nitric oxide pathway," Journal of the American College of Cardiology, vol. 34, no. 7, pp. 2111-2119, 1999. 
[58] A. Akula, M. K. Kota, S. G. Gopisetty et al., "Biochemical, histological and echocardiographic changes during experimental cardiomyopathy in STZ-induced diabetic rats," Pharmacological Research, vol. 48, no. 5, pp. 429-435, 2003.

[59] J. Wang, H. Wang, P. Hao et al., "Inhibition of aldehyde dehydrogenase 2 by oxidative stress is associated with cardiac dysfunction in diabetic rats," Molecular Medicine, vol. 17, no. 34, pp. 172-179, 2011.

[60] A. I. M. Al-Shafei, R. G. Wise, G. A. Gresham, T. A. Carpenter, L. D. Hall, and C. L.-H. Huang, "Magnetic resonance imaging analysis of cardiac cycle events in diabetic rats: the effect of angiotensin-converting enzyme inhibition," The Journal of Physiology, vol. 538, no. 2, pp. 555-572, 2002.

[61] R. Loganathan, M. Bilgen, B. Al-Hafez, M. D. Alenezy, and I. V. Smirnova, "Cardiac dysfunction in the diabetic rat: quantitative evaluation using high resolution magnetic resonance imaging," Cardiovascular Diabetology, vol. 5, article 7, 2006.

[62] S. F. Nagueh, C. P. Appleton, T. C. Gillebert et al., "Recommendations for the evaluation of left ventricular diastolic function by echocardiography," Journal of the American Society of Echocardiography, vol. 22, no. 2, pp. 107-133, 2009.

[63] M. F. da Silva, M. do Carmo Gouveia Pelúzio, P. R. dos Santos Amorim et al., "Swimming training attenuates contractile dysfunction in diabetic rat cardiomyocytes," Arquivos Brasileiros de Cardiologia, vol. 97, no. 1, pp. 33-39, 2011.

[64] E. Bollano, E. Omerovic, H. Svensson, F. Waagstein, and M. Fu, "Cardiac remodeling rather than disturbed myocardial energy metabolism is associated with cardiac dysfunction in diabetic rats," International Journal of Cardiology, vol. 114, no. 2, pp. 195201, 2007.

[65] E. Silva, A. J. Natali, M. F. Silva et al., "Ventricular remodeling in growing rats with experimental diabetes: the impact of swimming training," Pathology Research and Practice, vol. 209, no. 10, pp. 618-626, 2013.

[66] N. Kaul, N. Siveski-Iliskovic, T. P. Thomas, M. Hill, N. Khaper, and P. K. Singal, "Probucol improves antioxidant activity and modulates development of diabetic cardiomyopathy," Nutrition, vol. 11, no. 5, pp. 551-554, 1995.

[67] S. Altenhöfer, K. A. Radermacher, P. W. M. Kleikers, K. Wingler, and H. H. Schmidt, "Evolution of NADPH oxidase inhibitors: selectivity and mechanisms for target engagement," Antioxidants \& Redox Signaling, 2014.

[68] G. Bjelakovic, D. Nikolova, L. L. Gluud, R. G. Simonetti, and C. Gluud, "Mortality in randomized trials of antioxidant supplements for primary and secondary prevention: systematic review and meta-analysis," The Journal of the American Medical Association, vol. 297, no. 8, pp. 842-857, 2007.

[69] F. Farhat, J. Dupas, A. Amérand et al., "Effect of exercise training on oxidative stress and mitochondrial function in rat heart and gastrocnemius muscle," Redox Report, 2014.

[70] L. A. Silva, C. A. Pinho, K. S. Scarabelot et al., "Physical exercise increases mitochondrial function and reduces oxidative damage in skeletal muscle," European Journal of Applied Physiology, vol. 105, no. 6, pp. 861-867, 2009. 


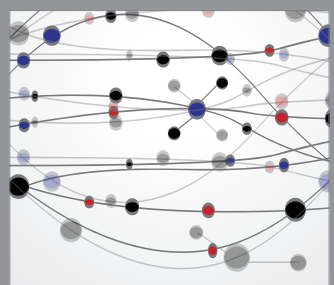

The Scientific World Journal
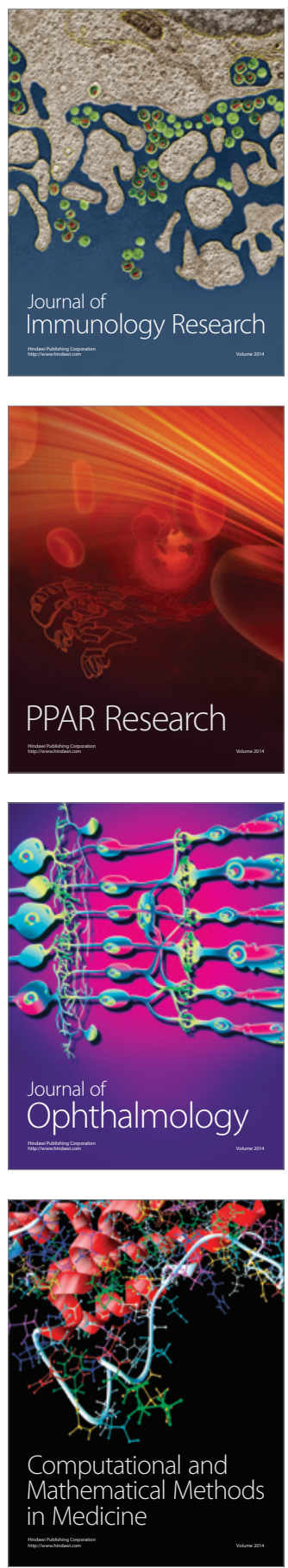

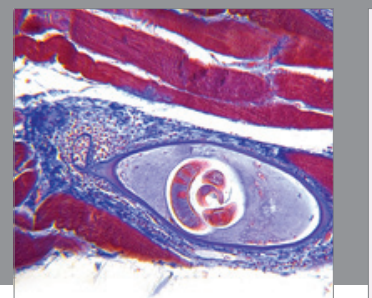

Gastroenterology

Research and Practice
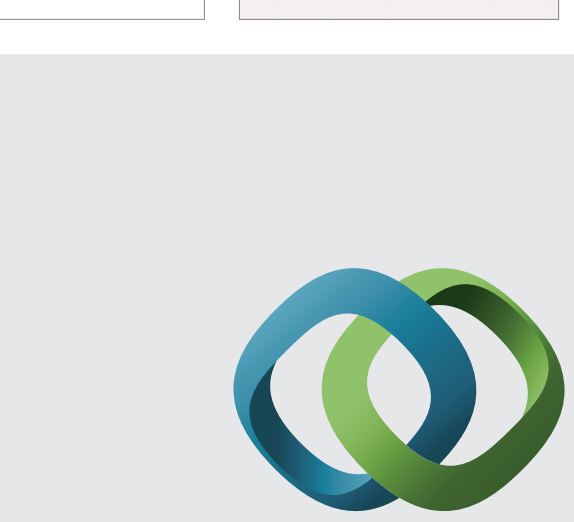

\section{Hindawi}

Submit your manuscripts at

http://www.hindawi.com
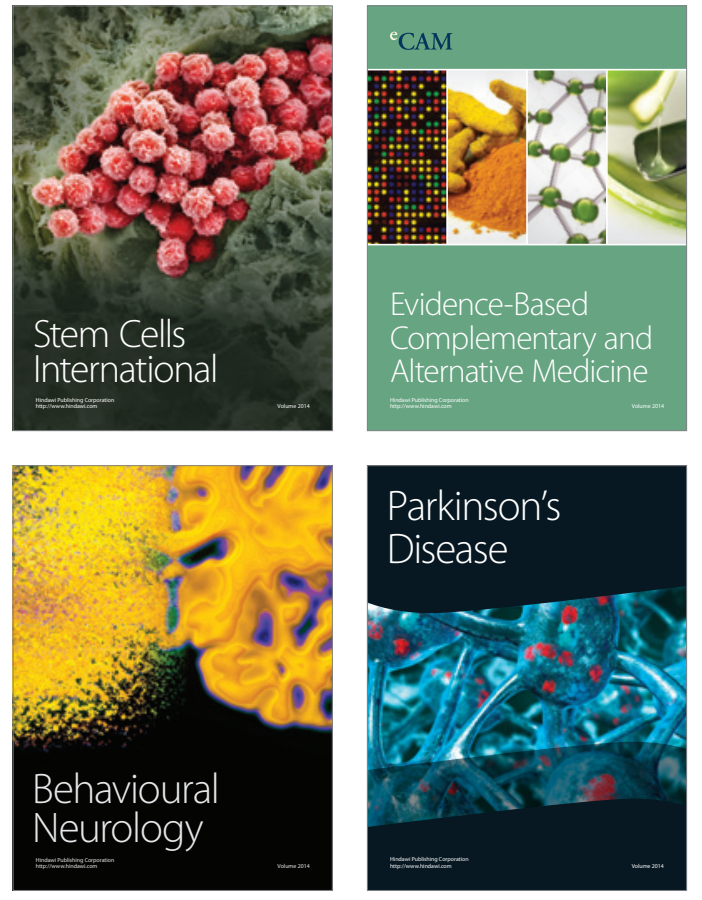
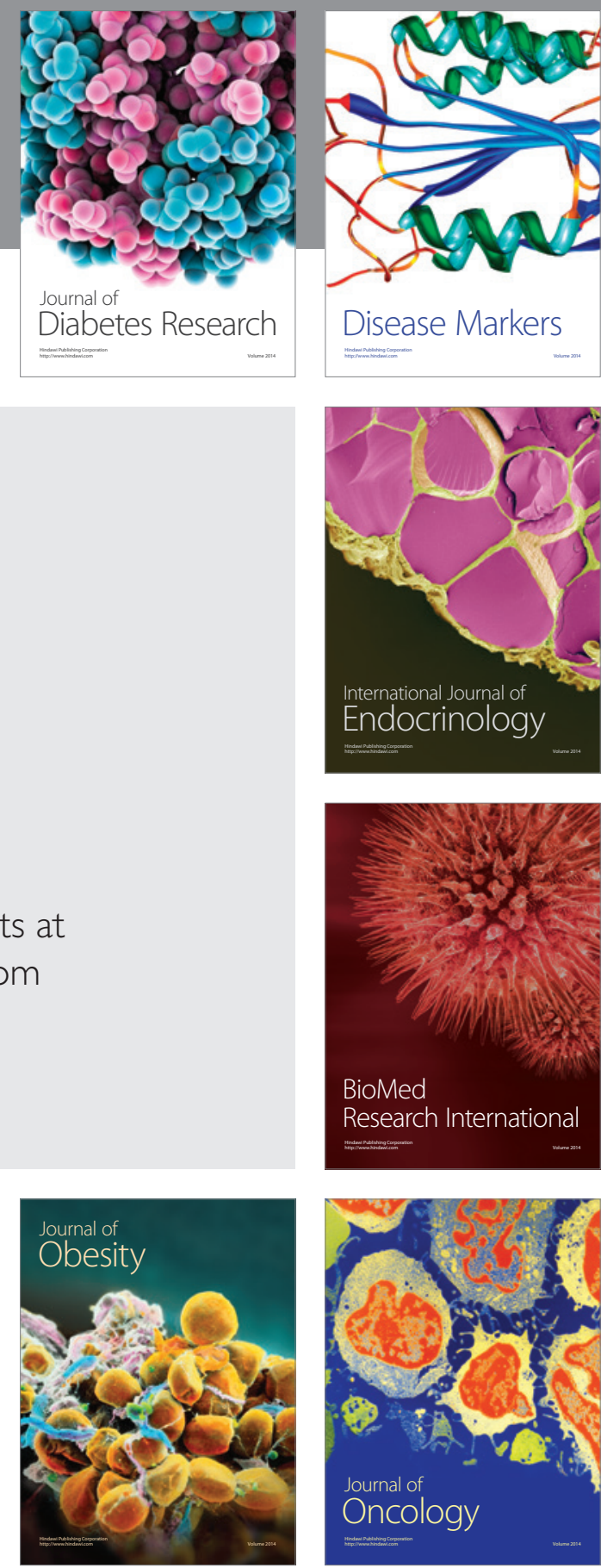

Disease Markers
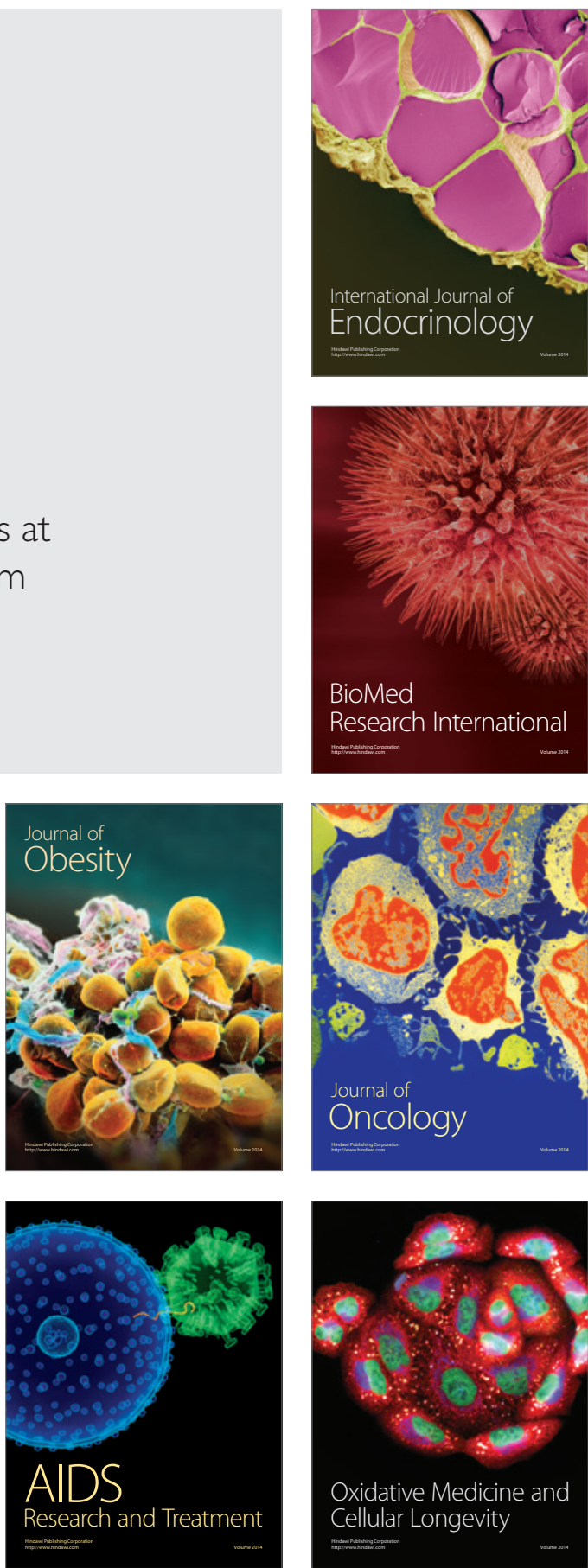